\title{
Conflict resolution strategies of nurses in a selected government tertiary hospital in the Kingdom of Saudi Arabia
}

\author{
Fatma Baddar ${ }^{1,2}$, Olfat A. Salem ${ }^{* 1,3}$, Hazel N. Villagracia ${ }^{1}$ \\ ${ }^{1}$ Nursing Administration and Education Department, College of Nursing, King Saud University, Riyadh, Kingdom of Saudi Arabia \\ ${ }^{2}$ Nursing Administration Department, Faculty of Nursing, Alexandria University, Alexandria, Egypt \\ ${ }^{3}$ Nursing Administration Department, Faculty of Nursing, Menoufia University, Menoufia, Egypt
}

Received: November 15, 2015

Accepted: January 8, 2016

Online Published: January 14, 2016

DOI: $10.5430 /$ jnep.v6n5p91

URL: http://dx.doi.org/10.5430/jnep.v6n5p91

\begin{abstract}
Background: Conflict is inevitable and can be found in all settings. It can co-exist between and among health care professionals such as doctors and nurses and their patients. The roles of the nurses in each scenario and the kind of strategies they utilized also vary. This study aimed to determine the conflict resolution strategies of nurses in a selected government tertiary hospital in the Kingdom of Saudi Arabia.

Methods: Utilizing a Descriptive Correlational Research Design, 78 nurses were asked to identify their conflict resolution strategies during their day to day interaction with the patients and doctors through a 20-item questionnaire. This study was conducted in a government tertiary hospital specializing in maternity and pediatric care with 310 beds in the East of Riyadh.

Results: Findings yielded a high utilization of conflict resolution strategies by nurses with patients. Accommodating $(61.5 \% ; \mathrm{n}=$ 48) was ranked number one as nurses used this strategy in dealing with patients. Secondly, collaborative $(60.3 \% ; n=47)$, the third is both compromising and avoiding at $(57.7 \% ; \mathrm{n}=45)$; and the least in rank is competing $(56.4 \% ; \mathrm{n}=44)$. Nurses utilized the following conflict resolution strategies with doctors such as: (1) competing $(43.6 \% ; \mathrm{n}=34)$, (2) both compromising and avoiding (42.3\%; $\mathrm{n}=33)$, (3) collaborative $(39.7 \% ; \mathrm{n}=31)$, and (4) accommodating $(38.5 \% ; \mathrm{n}=3)$. It shows that the number 1 priority for conflict resolution strategies is "accommodating" for patients which was regarded the least for the doctors. On the other hand, the least strategy "competing" with patients is the number 1 strategy of nurses with doctors. There is a significant relationship between nurses' use of conflict resolution strategies consistent at collaborative with patients and doctors and their age. Findings further reveal that the overall use of conflict resolution strategies is significantly related to both patients and doctors. There is a significant relationship between nurses' use of conflict resolution strategies at compromising with doctors and their nursing qualification. There is a significant relationship between nurses' use of conflict resolution strategies (collaborative) with patients and their current nursing experience. The overall use of compromising as a strategy is significantly related to doctors. There is a significant positive correlation between the nurses' scores of conflict resolution strategies for both patients and doctors. On the one hand, there is no significant difference relation between nurses' use of conflict resolution strategies with patients and doctors and their socio-demographic variables (age, years of nursing experience) except nursing qualification. There is a significant difference between nurses' use of conflict resolution strategies (avoiding) with patients and doctors and their qualifications.

Conclusions: Consequently, conflict is inevitable and is still growing in healthcare. We have determined the importance of identifying the conflict resolution strategies being utilized by nurses when they deal with their patients and doctors. Nurses can safely identify conflict and implement systems for its management. Nurses and doctors must establish positive collegial
\end{abstract}

*Correspondence: Olfat A. Salem; Email: osalem@KSU.EDU.SA; Address: Nursing Administration and Education Department, College of Nursing, King Saud University, Riyadh, Kingdom of Saudi Arabia.

Published by Sciedu Press 
relationships. The active management of conflict is an important aspect towards a positive collegial relationship. Doctors and nurses can effectively manage conflict to produce positive outcomes for patients.

Key Words: Conflict, Conflict resolution strategies, Nursing administration

\section{BACKGROUND}

Nursing conflict traditionally generated negative feelings that many nurses use avoidance as a coping mechanism. ${ }^{[1]}$ Conflict is one of the most experienced issues by nurses and other healthcare team members. In fact, the Nursing Administration is also faced with challenges in resolving conflicts within the units of their nurses, outside their units, with other departments and even with the Hospital Administration. Managing one's conflict in the workplace is time-consuming but necessary task for the nurses. Simple to a heavy intervention leading to litigationsin any hospital settings may occur in different types of conflicts. Conflicts have an adverse effect on the individual and organization such as productivity, morale, and patient care of all the healthcare team that might lead to a rapid turnover of employees or dissatisfaction. ${ }^{[2]}$

Viewing issues or situations from different perspectives, these relationships can be compromised by conflict. Such that, conflict is referred to as a power struggle in which a person intends to harass, neutralize, injure or eliminate a rival. ${ }^{[2]}$ According to Marshall (2006), "Conflict is neither good, nor bad, it just is", ${ }^{[3]}$ it can lead to positive and negative outcomes for nurses, their colleagues, patients and organization. If managed effectively by nurses, it can, while if ineffectively managed, teamwork, productivity and quality patient care can be compromised. There can be negative impact to the organization of the hospital and its goals.

There are several types of conflicts such as intrapersonal, interpersonal, intra-group, and inter-group, conflicts. ${ }^{[4]}$ Intrapersonal conflict is discord or dissention within an individual, it occurs when one is facing with two or more incompatible demands. Inter-personal conflict occurs between two or more individuals, whose values, goals, and beliefs are incompatible. Intra-group conflict occurs regularly within an established group, it may arise due to lack of support, new problem, which necessitate changes within group member roles and relationships, imposed values and role conflict inside the group. Inter-group conflict, arises between groups with differencing goals, the achievement of which by one group can occur at the expense of the other. ${ }^{[4,5]}$

Conflictsituation may be identified where at least two parties are involved, with different goals and/or values, where behaviors can lead toll defeat, reduce, or suppress the opponent, or gain a victory, with opposing actions and counteractions; and create in imbalance, or favored power position. ${ }^{[6]}$ Conflict resolution requires specific leadership skills, problem solving abilities and decision making skills. ${ }^{[7]}$ When conflicts go unaddressed, they can have a negative impact on productivity and teamwork. Using conflict resolution strategies in the workplace will help maintain a healthy work environment.

In a study on "workplace conflict resolution and the health of employees in the Swedish and Finnish units of an industrial company", it has been found out that new patterns of work can change the way employees work and the new environment can eliminate some risks while introducing others. In the study of Hyde, Jappinen, Theorell and Oxenstierna, importance of the psychosocial working environment for the health of employees is now well documented, but the effects of managerial strategy have received relatively little attention. These results suggested that the workplace conflict resolution is important to the traditional psychosocial work environment risk factors. ${ }^{[8]}$

Learning to respond to conflict is required in developing conflict resolution strategies. Nurses need to remember that the foundation of nursing care is the therapeutic nurse-patient relationship, which contributes to the patient's well-being and health. This therapeutic relationship can be threatened whenever there is conflict, either with the patient, the patients' family, the patients' friends, or colleagues. Nurses share the responsibility with their employers to create a healthy workplace environment, ensuring that conflict does not negatively affect the patients' health outcomes or the relationships among colleagues. ${ }^{[9]}$ Competing, Accommodating, Avoiding, Collaborating and Compromising are five modes for responding to conflict situations. ${ }^{[10]}$ A study conducted by Nayeri (2009), which aims to explore the experience of conflict as perceived by Iranian hospital nurses in Tehran, Islamic Republic of Iran. The emerging themes were: 1) the nurses' perceptions and reactions to conflict; 2) organizational structure; 3) hospital management style; 4) the nature and conditions of job assignment; 5) individual characteristics; 6) mutual understanding and interaction; and 7) the consequences of conflict. The first six themes describe the sources of the conflict as well as strategies to manage them. Further, Nayeri concluded that the sources of conflict are embedded in the characteristics of nurses and the nursing system, but at the same time these characteristics can be 
seen as strategies to resolve conflict. Further, Nayeri concluded that the sources of conflict can be seen as strategies to resolve conflict. ${ }^{[11]}$ Conflict is one of many issues found in any organization, including hospitals, where constant human interaction occurs. ${ }^{[12,13]}$ The sources of conflict among hospital nurses and health care personnel include authority positions and hierarchy, the ability to work as a team, interpersonal relationship skills, and the expectations of performing in various roles at various levels. ${ }^{[14]}$ Eason et al. and Bartol et al. emphasized on the recognition of conflict how to moderate and control them according to viewpoints. ${ }^{[15,16]} \mathrm{Yu}$ opined that addressing the conflict is enhances professional development and reduces burnout among nurses. ${ }^{[13]}$

Cox concluded that inadequate communication between medical practitioners and nurses can lead to conflicts, ${ }^{[17]}$ that not all the outcomes of conflict are negative; conflict can be constructive if it enhances decision-making quality. ${ }^{[17]}$ Skeels ${ }^{[18]}$ conducted a descriptive study on disruptive sources of conflict in the nursing unit and the conflict resolution mode most frequently used by nurses. Various levels of registered nurses employed at three acute care hospitals in Beaumont, Texas, in relation to conflict source to conflict resolution mode and hospital site. The voluntary participants completed the Thomas-Kilmann Conflict Mode Instrument and ranked disruptive sources of conflict prior to a program on conflict management. The findings from which were the most disruptive source of conflict were not clearly evident with all five possible sources listed having combined medians of 3 or 4. Clinical implications on patient care may be in jeopardy with nurses using primarily the non-assertive modes of compromising, avoiding, and accommodating rather than the more effective mode of collaboration. A greater awareness and careful choice by the nurse of the most effective conflict resolution mode is important. ${ }^{[18]}$ With these literatures and studies, we aimed to determine the conflict resolution strategies of the nurses in a selected government hospital.

\section{METHOD}

\subsection{Setting}

The study was carried out in a 310 beds capacity government tertiary hospital specializing in maternity and pediatric care in Riyadh City which affiliated with Ministry of Health $(\mathrm{MOH})$.

\subsection{Design}

Descriptive correlational research design was used for this study.

Published by Sciedu Press

\subsection{Participants}

The target population consisted of all nurses working in the selected hospital. The sampling consisted of nurses who were working in the selected hospital in Riyadh, during the time of the study. The sample size was calculated to estimate a mean score of 3 or higher (out of a maximum of 6), with an absolute precision of 0.25 using the MedCalc sample size calculator. ${ }^{[19]}$ Accordingly, the required sample size was 80 . This was increased to 100 to account for the design effect and a nonresponse rate of approximately 20\%.[20] Quota sampling was used with an allocation of 80 nurses from the selected hospital. A non-probability sample from all available staff nurses in these settings was recruited to fulfill the required sample sizes.

\subsection{Procedures}

Prior to data collection, an institutional review board was granted approval for the study. Before the study was conducted, the research team contacted through email the Director of the Research Center in the selected hospital and explained the study procedures. Questionnaires were emailed to the Nursing supervisors of the selected hospital to be given to nurses in the wards. The questionnaires accompanied by a letter to each participant, explaining the objectives of the researchwere self-administered. Throughout the study, protection of human rights was assured, and adherence to ethical principles was secured, and ensured that each participant's autonomy was supported. Participation was voluntary, and there was no penalty for withdrawal from or termination of the study. In addition, the research methodologies were non-invasive, and there were minimal or no anticipated risks to participants. A consent form was obtained from all participants. Total confidentiality of information was also ascertained.

\subsection{Data collection tool}

For the purpose of this study, the operational definition of Conflict according to Elliot is "an internal individual struggle resulting from incompatible or opposing needs, drives, or external and internal demands. In group interactions, competitive or opposing action of incompatibles" while, Conflict Resolution Strategies "are the approaches utilizing five styles: avoiding, competing, accommodating, compromising and collaborative." ${ }^{21]}$ The data collection tool was adapted from Elliot (2010) with 20 items divided into five subscales namely avoiding, competing, accommodating, compromising and collaborative. Further, the conflict resolution in English form was used to determine the conflict resolution strategies of the nurses in a selected government hospital. This tool consists of 20 items that measure the five components of Conflict Resolution Strategies such as : Collaborating (4 items), 
Competing (4 items), Compromising (4 items), Avoiding (4 items), and Accommodating (4 items). Each item is rated on a 6-point Likert scale. A section was added for the respondents' personal characteristics, specifically, age, total Nursing years of experience and the years of experience in the current job.

\subsection{Ethical considerations}

Before using questionnaire, the researcher obtained permission from the authors. The study protocol was approved by the Research and Ethics Committee. All principles of ethics in research were followed. The data collection tool had a cover page that explained the aim of the study and the participant's rights, such as refusal, confidentiality, anonymity, and the use of their information solely for research. Each participantwas then asked to sign the form as consent to participate.

\subsection{Statistical analysis}

Data entry and statistical analysis were performed using the Statistical Package for Social Sciences (SPSS) version 16.0. The data are presented using descriptive statistics in the form of frequencies and percentages for the qualitative variables and means and standard deviations and medians for the quantitative variables. Cronbach's alpha coefficient was calculated to assess the reliability of the developed tools through their internal consistency. $\chi^{2}$ test and The Spearman rank correlation was used at a $p$-value $<.05$ to test its statistical significance.

\section{Results}

From the present study sample, the profile showed a majority of age less than 30 years old, and a mean of 29.1; $51(65.4 \%)$ as majority earned a bachelor's degree; 42 (53.8\%) have more than 5 years of experience in the institution, with a mean of 4.8 and 46 (59\%) with more than 5 years in nursing, a mean of 5.6 (see Table 1).

We have determined the importance of identifying the conflict resolution strategies being utilized by nurses when they deal with their patients and doctors. Generally, findings yielded a high utilization of conflict resolution strategies by nurses with patients and doctors. Accommodating (61.5\%; n $=48$ ) was ranked number one as nurses used this strategy in dealing with patients. Secondly, collaborative $(60.3 \%$; $\mathrm{n}=$ $47)$, the third is both compromising and avoiding at (57.7\%; $\mathrm{n}=45)$; and the least in rank is competing $(56.4 \% ; \mathrm{n}=44)$.
Table 1. Socio-demographic characteristics of nurses in the study sample $(n=78)$

\begin{tabular}{lll}
\hline Categories & Frequency & Percent (\%) \\
\hline Age & & \\
$\quad<30$ & 50 & 64.1 \\
$30+$ & 28 & 35.9 \\
Range & $21.0-55.0$ & \\
Mean \pm SD & $29.1 \pm 5.4$ & \\
Median & 28.00 & \\
Nursing qualification & & \\
$\quad$ Diploma & 27 & 34.6 \\
Bachelor & 51 & 65.4 \\
Experience in institution (years) & & \\
$\quad<5$ & 42 & 53.8 \\
$5+$ & 36 & 46.2 \\
Mean \pm SD & $4.8 \pm 3.4$ & \\
Median & 4.00 & \\
Experience in nursing (years) & & \\
$<5$ & 32 & 41.0 \\
$5+$ & 46 & 59.0 \\
Mean \pm SD & $5.6 \pm 4.4$ \\
Median & 6.00 & \\
\hline
\end{tabular}

Nurses utilized the following conflict resolution strategies with doctors such as: first, is competing $(43.6 \% ; n=34)$, second is both compromising and avoiding $(42.3 \% ; n=33)$, third, collaborative $(39.7 \% ; \mathrm{n}=31)$, and the least is accommodating $(38.5 \% ; n=3)$. It shows that the number 1 priority for conflict resolution strategies is "accommodating" for patients which was regarded the least for the doctors. On the other hand, the least strategy "competing" with patients is the number 1 strategy of nurses with doctors (see Table 2).

Table 2. Frequency and percentage distribution in the conflict resolution strategies used by nurses with patients and doctors

\begin{tabular}{lll}
\hline $\begin{array}{l}\text { High (5+) use of conflict } \\
\text { resolution strategies }\end{array}$ & Frequency & Percent (\%) \\
\hline $\begin{array}{l}\text { More collaborative with } \\
\text { Doctors }\end{array}$ & 31 & 39.7 \\
$\quad$ Patients & 47 & 60.3 \\
More accommodating with & & \\
$\quad$ Doctors & 30 & 38.5 \\
$\quad$ Patients & 48 & 61.5 \\
More competing with & & \\
$\quad$ Doctors & 34 & 43.6 \\
$\quad$ Patients & 44 & 56.4 \\
More compromising with & & \\
$\quad$ Doctors & 33 & 42.3 \\
$\quad$ Patients & 45 & 57.7 \\
More avoiding with & & \\
$\quad$ Doctors & 33 & 42.3 \\
$\quad$ Patients & 45 & 57.7 \\
\hline
\end{tabular}


Table 3 shows that there is a significant relationship between the overall use of conflict resolution strategies is significantly nurses' use of conflict resolution strategies consistent at col- related to both patients with $\chi^{2}$ value of $6.19, p<.01$ and laborative with patients and doctors and their age with $p$ both patients with $\chi^{2}$ value of $4.63, p<.03$.

values of $.01, .03$, respectively. Findings further reveal that

Table 3. Nurses' use of conflict resolution strategies with patients and doctors and their age

\begin{tabular}{|c|c|c|c|c|c|c|}
\hline & \multicolumn{4}{|l|}{ Age } & \multirow{3}{*}{$\chi^{2}$ test } & \multirow{3}{*}{$p$-value } \\
\hline & \multicolumn{2}{|c|}{$<\mathbf{3 0}$} & \multicolumn{2}{|l|}{$30+$} & & \\
\hline & No. & $\%$ & No. & $\%$ & & \\
\hline \multicolumn{7}{|l|}{ With patients } \\
\hline Collaborative & 6 & 12.0 & 10 & 35.7 & 6.19 & $.01 *$ \\
\hline Accommodating & 5 & 10.0 & 8 & 28.6 & Fisher & .06 \\
\hline Competitive & 4 & 8.0 & 7 & 25.0 & Fisher & .049 \\
\hline Compromising & 7 & 14.0 & 8 & 28.6 & 2.45 & .12 \\
\hline Avoiding & 4 & 8.0 & 4 & 14.3 & Fisher & .45 \\
\hline \multicolumn{7}{|l|}{ With doctors } \\
\hline Collaborative & 10 & 20.0 & 12 & 42.9 & 4.63 & $.03 *$ \\
\hline Accommodating & 12 & 24.0 & 10 & 35.7 & 1.22 & .27 \\
\hline Competitive & 10 & 20.0 & 7 & 25.0 & 0.26 & .61 \\
\hline Compromising & 9 & 18.0 & 9 & 32.1 & 2.02 & .15 \\
\hline Avoiding & 9 & 18.0 & 5 & 17.9 & 0.00 & .99 \\
\hline
\end{tabular}

Statistically significant at $* p<.05$

In Table 4, there is a significant relationship between nurses' use of conflict resolution strategies at compromising with doctors and their nursing qualification. Findings further reveal that the overall use of compromising as a strategy is significantly related to doctors with $\chi^{2}$ value of 4.23 .

Table 5 reveals that there is no significant relationship between nurses' use of conflict resolution strategies with doctors and their total nursing experience.

Table 4. Nurses' use of conflict resolution strategies with patients and doctors and their nursing qualification

\begin{tabular}{|c|c|c|c|c|c|c|}
\hline & \multicolumn{4}{|c|}{ Qualification } & \multirow{3}{*}{$\chi^{2}$ test } & \multirow{3}{*}{$p$-value } \\
\hline & \multicolumn{2}{|c|}{ Diploma } & \multicolumn{2}{|c|}{ Bachelor } & & \\
\hline & No. & $\%$ & No. & $\%$ & & \\
\hline \multicolumn{7}{|l|}{ With patients } \\
\hline Collaborative & 8 & 29.6 & 8 & 15.7 & 2.10 & .15 \\
\hline Accommodating & 6 & 22.2 & 7 & 13.7 & Fisher & .36 \\
\hline Competitive & 4 & 14.8 & 7 & 13.7 & Fisher & 1.00 \\
\hline Compromising & 7 & 25.9 & 8 & 15.7 & 1.19 & .27 \\
\hline Avoiding & 2 & 7.4 & 6 & 11.8 & Fisher & .71 \\
\hline \multicolumn{7}{|l|}{ With doctors } \\
\hline Collaborative & 11 & 40.7 & 11 & 21.6 & 3.20 & .07 \\
\hline Accommodating & 11 & 40.7 & 11 & 21.6 & 3.20 & .07 \\
\hline Competitive & 9 & 33.3 & 8 & 15.7 & 3.23 & .07 \\
\hline Compromising & 10 & 37.0 & 8 & 15.7 & 4.53 & $.03^{*}$ \\
\hline Avoiding & 7 & 25.9 & 7 & 13.7 & Fisher & .22 \\
\hline
\end{tabular}

Statistically significant at $* p<.05$ 
Table 5. Nurses' use of conflict resolution strategies with patients and doctors and their total nursing experience

\begin{tabular}{|c|c|c|c|c|c|c|}
\hline & \multicolumn{4}{|c|}{ Total Nursing experience years } & \multirow{3}{*}{$\chi^{2}$ test } & \multirow{3}{*}{$p$-value } \\
\hline & \multicolumn{2}{|l|}{$<5$} & \multicolumn{2}{|l|}{$5+$} & & \\
\hline & No. & $\%$ & No. & $\%$ & & \\
\hline \multicolumn{7}{|l|}{ With patients } \\
\hline Collaborative & 7 & 16.7 & 9 & 25.0 & 0.83 & .36 \\
\hline Accommodating & 6 & 14.3 & 7 & 19.4 & 0.37 & .54 \\
\hline Competitive & 5 & 11.9 & 6 & 16.7 & 0.36 & .55 \\
\hline Compromising & 8 & 21.4 & 6 & 16.7 & 0.28 & .59 \\
\hline Avoiding & 3 & 7.1 & 5 & 13.9 & Fisher & .46 \\
\hline \multicolumn{7}{|l|}{ With doctors } \\
\hline Collaborative & 12 & 28.6 & 10 & 27.8 & 0.01 & .94 \\
\hline Accommodating & 13 & 31.0 & 9 & 25.0 & 0.34 & .56 \\
\hline Competitive & 11 & 26.2 & 6 & 16.7 & 1.03 & .31 \\
\hline Compromising & 10 & 23.8 & 8 & 22.2 & 0.03 & .87 \\
\hline Avoiding & 8 & 19.0 & 6 & 16.7 & 0.07 & .78 \\
\hline
\end{tabular}

\section{DiscuSsion}

Nurses and doctors deal with conflicts daily. The findings of this current study yielded a high utilization of conflict resolution strategies by nurses with patients $(61.5 \%)$ was accommodation, followed by collaboration $(60.3 \%)$, and the least strategy utilized by nurses with patients in rank was competing (56.4\%). This result may provide evidence that the profession is based on collaborative relationships where nurses are able to select strategies in different situations in conflict resolution that may reflect the value they place on the importance of relationship with patients. Nurses have high concern for patients, attends very closely to their needs and ignores her or his own needs. While collaboration is the most preferred of the conflict strategies, it involves attending to others' concerns while not sacrificing one's own concerns. By using these strategies, nurses may try to avoid stress, tension, which may arise from conflict situation in order to decrease the intensity of conflict.

According to Blake and Mouten, ${ }^{[22]}$ accommodation, collaboration are used by individuals who want to move away from the uncomfortable feelings of struggle, similar with the studies of Cavanagh et al. ${ }^{[23-26]}$ On the other hand, with regard use of conflict resolution strategies by nurses with doctors, the study's findings revealed that the number one priority for conflict resolution strategies was "accommodating" for patients which was regarded the least for the doctors. Conversely, the least strategy "competing" with patients was the number one strategy of nurses with doctors. These results may attribute to the fact that doctors conflict with nurses are due to the changing, more advanced roles and the rejection of the traditional paradigm of doctor dominance. ${ }^{[27]}$
However, competitive approaches to conflict can have positive results but more often counterproductive than productive, whereas, attempting to solve conflict with dominance and control, communication can easily become negative, creating unstable situations. Competition can create discomfort which can direct energy away from patient care objectives toward unnecessary inter-professional struggles. This result is in line with the studies of Valentine et al. $^{[24,27,28]}$

Our study also revealed a significant relationship between nurses' use of conflict resolution strategies and their age, that young nurses less than 30 years old tend to make more use of the compromising conflict resolution strategies with patients and accommodating conflict resolution strategies with doctors while older generations prefer collaborative with both patients and doctors, with $p$-values of $.01, .03$, respectively. This may be attributed to the fact that young nurses seek other people approval, tend to have good or at least tolerable interpersonal relations with their patients, and disfavor having enemies in their working environment.

Therefore, compromising conflict resolution strategy for both nurses and doctors, brings medium benefits by not harming anyone. Moreover, conflict does not remain unsolved as when avoiding, there are no apparent winners at the expense of others as with Competing. While, accommodation strategies with doctors, might be appropriate for the nurses if they did not feel that their goals was so important. This feeling might be due to low self confidence in their views, decreased commitment to nursing profession, or a feeling that the other party of the conflict is stronger than them. In this manner, nurses can sacrifice their needs that let the doctors win over the conflict. We found out that the priority for conflict resolu- 
tion strategies among nurses is accommodating specifically for patients which was regarded the least for the doctors. Competing is the least strategy of nurses with patients while highest strategy of nurses with doctors.

On the same line Valentine, ${ }^{[24]}$ mentioned that the reason for women being more accommodating can be due to their inborn higher concern for others as a consequence of their inherited and historical roles may be several explanations for the findings of this study. The social cognitive theory proposes that behavior is affected by environmental influences, personal factors, and attributes of the behavior itself. Perhaps, environmental influences contribute to the accommodating conflict management strategies of the nurses with doctors in this study. ${ }^{[29]}$ In relation to old generation nurses, compromising may not result in such benefits as compared to collaborating. In this respect, managing conflict constructively, ${ }^{[30]}$ collaboration creates a win-win solution. Maximizing assertive, cooperative behaviors will promote collaboration rather than compromising. ${ }^{[31,32]}$

However, the findings of the current study are consistent with Antonioni's ${ }^{[33]}$ study results which showed that the older population prefer collaboration and compromising. On the other hand, the findings of this study is inconsistent with the finding of Nina, Sanja ${ }^{[34]}$ who reported that, the average score of conflict resolution strategies was for avoiding and competing, while highest in accommodating and compromising, and collaborating declines with age. Conversely, Gordon ${ }^{[35]}$ found no differences of conflict management strategies by age, all ages preferred the collaborative strategy.

Additionally, the current study indicated a significant relationship between nurses' use of conflict resolution strategies and qualification. It was found that nurses holding Diploma degree used compromising with doctors, while the Bachelor's degree nurses used collaborative strategy. Such results might be attributed to those nurses with higher level of education associated with nurse's age and experience which leads to higher expectations for managing conflict constructively. Using collaborating also, might be due to interpersonal conflict in the hospital between doctors, nurses, which needs accepting and understanding one another's needs and expectation to improve the quality of the relationships. Hendel et al. (2007) $)^{[36]}$ in their study found that collaborating was chosen significantly more frequently among qualified nurses. But, on the other hand, the results of the current study are inconsistent with Abudahi, Fekry \& Elwahab ${ }^{[37]}$ who revealed no statistical significant relationship between demographic characteristics such as age, experience and job, qualification and the used conflict management strategy. In addition, the findings of the present study indicated no sig-

Published by Sciedu Press nificant difference between nurses' use of conflict resolution strategies with patients and doctors and their total years of experience in nursing. This result inconsistent with the results of Hendel et al. ${ }^{[36]}$ which revealed that accommodation, avoiding and competing each had a statistically significant relationship with years of experience in current position. As years of experience in current position increased, the use of the accommodation, avoiding, and competing strategies also increased. When years of experience in current position increased, the use of the compromising conflict resolution strategies is decreased, but did not show a relationship to years of experience in current position.

\section{Study limitations}

Actual behaviors of the nurses were not directly observed. Behavioral measures such as direct observations, peer assessment and related methods can be added in future studies in order to assess the actual conflict handling strategies. The study was conducted in only one specialized hospital accredited by the Ministry of Health, and the sample was selected conveniently. Therefore, the results cannot be generalized. A bigger sample population in more than one hospital is recommended.

\section{CONCLUSIONS AND RECOMMENDATIONS}

Consequently, conflict is inevitable and is still growing in healthcare. We have determined the importance of identifying the conflict resolution strategies being utilized by nurses when they deal with their patients and doctors. Nurses can safely identify conflict and implement systems for its management. Nurses and doctors must establish positive collegial relationships. The active management of conflict is an important aspect towards a positive collegial relationships. Doctors and nurses can effectively manage conflict to produces positive outcomes for patients.

It is recommended for future studies. Firstly, since doctors and nurses are partners in the delivery of quality care to patients, sharing the responsibility can create a healthy workplace. Such that Conflict Resolution Strategy Model can be developed to measure extent of collaboration and compromising between and among nurses, doctors and patients. This will improve health outcomes. Secondly, more researches are recommended on the personality, organizational environment and conflict management. Exploring variables on conflict handling strategies and work measures. Lastly, exploration on conflict management abilities and skills among undergraduate and graduate students.

Nurses are in a crucial role for determining the appropriate strategies in managing conflicts. A clearer understanding of the factors underlying conflict resolution strategies can 
be considered. Better management program, hand in hand with Human Resource Department and Nursing Service can promote positive outcomes. Finding time to contribute to the nursing knowledge while intervening in a fast-paced healthcare environment is the ultimate challenge for staff nurses but also to nursing administrators.

\section{ACKNOWLEDGEMENTS}

This research project was supported by a grant from the "Research Center of the College of Nursing", Deanship of Scientific Research, King Saud University.

\section{CONFLicts OF InTEREST Disclosure}

The authors declare that there is no conflict of interest.

\section{REFERENCES}

[1] College of Nursing Ontario. 2009. Available from: http://www.nc bi.nlm.nih.gov/pubmed/16501367

[2] Sportsman S. Build a framework for conflict assessment. Nursing Management. 2005; 4(36): 32-40. http://dx.doi.org/10.1097 /00006247-200504000-00011

[3] Marshall P. The case for mediation in health care. Conflict Resolution Today: Special HealthCare Edition. 2006; 18: 8-12.

[4] Sullivan K. Leadership skills for the nurse manager. NewYork: Richard D Irwin Higher Education Group Co. 1996.

[5] Conerly K. What is your conflict strategy? Understanding and dealing with your conflict strategy. Journal for Quality and Participation. 2004.

[6] Filley AC. Ethiopia Public Health Training Initiative, The Carter Center, the Ethiopia Ministry of Health, and the Ethiopia Ministry of Education. Amsale Cherie and A to Berhane Gebrekidan. 1975.

[7] University of Colorado. 2008. Available from: http://hr.color ado.edu/Pages/How_to_Reach_Us.aspx

[8] Hyde M, Jappinen P, Theorell T, et al. Workplace conflict resolution and the health of employees in the Swedish and Finnish units of an industrial company. Soc Sci Med. 2006 Oct; 63(8): 221827. PMid:16782255 http://dx.doi.org/10.1016/j.socscim ed.2006.05.002

[9] College of Nurses of Ontario. Conflict prevention and standard of care. Practice Guideline. 2006. 1-16.

[10] Thomas KW, Kilmann RH. An Overview of the ThomasKilmann Conflict Mode Instrument (TKI). Available from: http://www.kilmanndiagnostics.com/overview-thoma s-kilmann-conflict-mode-instrument-tki

[11] Nayeri ND, Negarandeh R. Conflict among Iranian hospital nurses: a qualitative study. 2009. Available from: http://www.ncbi.nlm .nih.gov/pmc/articles/PMC2667395/

[12] Johnson M. Conflict and nursing professionalization. In: McCloskey J, Grace H, editor. Current Issues in Nursing. St Louis: Mosby; 1994. 643-649 p.

[13] Yu X, Davidhizar R. Conflict management strategies of Asian and Asian American nurses: implications for the nurse manager. The Health Care Manager. 2004; 23: 46-53. http://dx. doi .org/10. 1097/00126450-200401000-00009

[14] Pranulis MF, Renwanz-Boyle A, Kontas AS, et al. Identifying nurses vulnerable to role conflict. Int Nurs Rev. 1995; 42: 45-50. PMid:7797406

[15] Eason FR, Brown ST. Conflict management: Assessing education needs. Journal for Nurses in Staff Development. 1999; 15: 92-96. PMid:10531894 http://dx.doi.org/10.1097/00124645-199 905000-00001

[16] Bartol GM, Parrish RS, McSweeney M. Effective conflict management begins with knowing your strategy. Journal for Nurses in Staff
Development. 2001; 17: 34-40. http://dx.doi.org/10.1097/0 0124645-200101000-00008

[17] Cox KB. The effects of unit morale and interpersonal relations on conflict in the nursing unit. J Adv Nurs. 2001; 35: 17-25. PMid:11442678 http://dx.doi.org/10.1046/j.1365-2648.2001.01819.x

[18] Skeels M. Methods of conflict management used by nurses in the hospital setting. 1994. Available from: http://www. nursinglib rary.org/vhl/handle/10755/223033/browse?type=autho r\&order $=$ ASC\&rpp $=20 \& v a l u e=$ Skeels $\% 2 C+$ Mary

[19] MedCalc. Easy-to-Use Statistical Software. Version 13.1.2. Last modified: April 10, 2014 (C) 1993-2014. Available from: https: //www .medcalc.org/manual/sampling_introduction.php

[20] Sakpal T. Sample Size Estimation in Clinical Trial. Perspect Clin Res. 2010; 1(2): 67-69. PMid:21829786

[21] Elliot J. Strategies for Managing Conflict Workshop. Wellesley Institute. 2010.

[22] Blake R, Mouton J. Theory and research for developing a science of leadership. J App Beh Scie. 1982; 18(3): 275-91. http: //dx.doi.org/10.1177/002188638201800304

[23] Cavanagh J. The conflict management strategies of staff nurses and nurse managers. J Advan. Nur. 1991; 10(3): 35-44.

[24] Valentine P. A gender perspective on conflict management strategies of nurses. Journal of Nursing Scholarship. 2001; 33: 69-74. http://dx.doi.org/10.1111/j.1547-5069.2001.00069.x

[25] Vivar C. Putting conflict management into practice: a nursing case study. Journal of Nursing Management. 2005; 14: 201206. PMid: 16600008 http://dx.doi.org/10.1111/j.1365-2 $934.2006 .00554 . x$

[26] Kelly J. An overview of conflict. Dimensions of Critical Care Nursing. 2006; 25: 22-28. http://dx.doi .org/10.1097/00003465-200 601000-00007

[27] Kaitelidou D, Kontogianni A, Galanis P, et al. Conflict management and job satisfaction in paediatric hospitals in Greece. Journal of Nursing Management. 2012; 20: 571-578. PMid:22591158 http://dx.doi.org/10.1111/j.1365-2834.2011.01196.x

[28] Jones A. Job conflict resolution styles of Nursrs. J Nurs Admin. 1992; 22(11): 63. PMid:1432231

[29] Whitworth BS. Conflict-handling Strategies? An exploratory Study of Registered Nurses in Southern Mississippi. Ph dissertation, Capella University. 2005.

[30] Deutsch M. Cooperation and competition. In The Handbook of Conflict Resolution Theory and Practice (M. Deutsch \& P.T. Coleman eds). San Francisco, CA: Jossey-Bass Publishers; 2000. 21-40 p.

[31] Barton A. Conflict resolution by nurse managers. Nursing Management. 1991; 22(5): 83-86. http://dx.doi.org/10.1097/00006 247-199105000-00019

[32] Marquis BK, Huston CJ. Leadership Roles and Managers Function in Nursing, 2nd ed. Lippincott, Philadelphia. 1996. 
[33] Antonioni D. Relationship between the big five personality factors and conflict management strategies. International Journal of Conflict Management. 1998; 9(4): 336-355. http://dx.doi.org/10.11 08/eb022814

[34] Nina P, Sanja S. The relationship between individual characteristics and conflict handling strategies-the case of Croatia. Problems and Perspectives in Management. 2000; 8(3).

[35] Gordon PA. Examining conflict management strategy preferences of practitioner faculty by gender and age (Doctoral dissertation, North central University, 2008). Retrieved from Dissertations \& Theses: Full Text database. 2008.

[36] Hendel T, Fish M, Berger O. Nurse physician conflict management model choices, implication for improved collaborative practice. Nurse Adminstration Quality. 2007; 31(3): 244-253. PMid:17607137 http: //dx.doi.org/10.1097/01.NAQ.0000278938.57115.75

[37] Abudahi A, Fekry N, Elwahab E. Relationship between Perceived Organizational Climate and Conflict Management Strategies among Nurses in Cairo University Hospitals. 2012. 